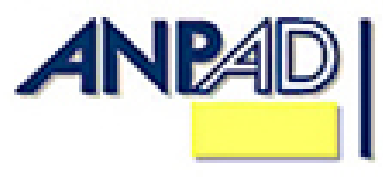

Disponível em

http://www.anpad.org.br/rac

RAC, Rio de Janeiro, v. 18, n. 1, art. 1,

pp. 1-19, Jan./Fev. 2014

(oc) EY-No

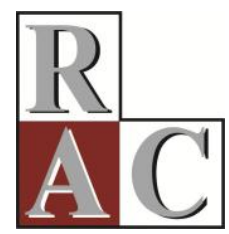

\title{
Burocrata Proteano: Articulações de Carreira em torno e além do Setor Público
}

\section{Protean Bureaucrats: Career Articulations within and beyond the Public Sector}

Josélia Rita da Silva

E-mail: joseliaamaral@gmail.com

Fucape Business School

Av. Fernando Ferrari, 1358, 29075-505, Vitória, ES, Brasil.

Moisés Balassiano

E-mail: moises@fucape.br

Fucape Business School

Av. Fernando Ferrari, 1358, 29075-505, Vitória, ES, Brasil.

Alfredo Rodrigues Leite da Silva

E-mail: alfredoufes@gmail.com

Universidade Federal do Espírito Santo - CCJE/UFES

Av. Fernando Ferrari, 514, CCJE/Depto. de Administração, 29075-910, Vitória, ES, Brasil.

Artigo recebido em 14.08.2012. Última versão recebida em 06.05.2013. Aprovado em 11.05.2013. 


\title{
Resumo
}

A maneira como as carreiras são construídas no setor privado vem sendo objeto de investigação exaustiva ao longo dos últimos vinte anos (Bendassolli, 2009; Chanlat, 1995, 1996). A compreensão sobre o matiz de como tais construções têm operado no setor público brasileiro ainda constitui uma lacuna na literatura atual sobre o tema (Bresser-Pereira, 1996; Saravia, 2006). O objetivo deste artigo é compreender como são construídos os processos pessoais de carreira de servidores com carreiras técnicas de nível superior no setor público, frente às diferentes perspectivas de carreiras articuladas no contexto social contemporâneo. Por meio de um estudo de caso descritivo, em um recorte qualitativo, buscou-se identificar a existência de características proteanas e mudanças de atitude a elas relacionadas, comumente associadas ao setor privado (Hall \& Moss, 1998), nos servidores de uma Secretaria de Estado que trata da gestão de recursos humanos em um estado brasileiro. A coleta de dados foi realizada por meio de entrevistas semiestruturadas. Dois grupos foram selecionados para compor os sujeitos de pesquisa, um com quinze servidores ativos e outro com cinco ex-servidores que pediram demissão. O tratamento dos dados foi realizado por meio da Análise do Conteúdo das entrevistas em uma abordagem temática (Bardin, 1979; Minayo, 2007). Os resultados revelam o rompimento da lógica da construção de carreira do setor público no contexto investigado, com servidores em busca de uma carreira sem fronteiras, vinculada às suas perspectivas pessoais.

Palavras-chave: carreiras; carreiras proteanas; carreiras no setor público.

\begin{abstract}
The way the careers are built in the private sector has been object of a massive amount of investigation over the last twenty years or so (Bendassoli, 2009; Chanlat, 1995, 1996). Comprehension of the way this has occurred in the Brazilian public sector constitutes a gap in the current literature on the theme (Bresser-Pereira, 1996; Saravia, 2006). This article aims to understand how high-level technical civil servants build their careers, in light of different perspectives of careers as articulated in current social context. It delved to identify the existence of protean features exhibited by civil servants, in order to characterize a possible change of attitude, something more commonly associated with the private sector (Hall \& Moss, 1998). Two groups were selected, one with current civil servants and another with former civil servants, all from a Brazilian state's Department of Human Resources. The subjects, all with college degrees in different fields, were interviewed using a semi-structured questionnaire. Resulting data was subjected to Content Analysis (Bardin, 1979; Minayo, 2007). A disruption of the logic of building a career in the public sector was observed, with servers searching for careers without boundaries, but linked to their personal perspectives; a logic commonly observed in the private sector.
\end{abstract}

Key words: careers; protean careers; public sector careers. 


\section{Introdução}

As carreiras podem ser compreendidas sob duas dimensões: a organizacional, englobando as estruturas, rotinas e padrões formais; e a individual, abordando os aspectos subjetivos e estratégicos na visão da pessoa (Bendassolli, 2009; Schein, 1984). Em relação a essas duas dimensões, as carreiras acompanham um sistema social maior, evoluindo como resposta às transformações ocorridas na sociedade, na economia e na política (Bendassolli, 2009; Chanlat, 1995, 1996). Tais mudanças acarretam impactos na forma como as organizações e os trabalhadores se relacionam, redefinindo as relações entre o capital e o trabalho.

A redução do número de trabalhadores, o tempo e a continuidade das relações entre organizações e indivíduos têm gerado novos contratos e relações, mudando, inclusive, a própria natureza do trabalho (Carvalho, 1997). Todavia, os estudos que demonstram tais alterações nos formatos, conteúdos e perspectivas das carreiras são, na sua grande maioria, relacionados diretamente ao setor privado, sem tratar de especificidades do setor público.

No caso brasileiro, o setor público é alicerçado por um alto grau de regulamentação e mecanismos burocráticos, convivendo apenas com algumas tentativas de implementação de novas formas de organização que, segundo Carvalho (1997), são frutos de uma mudança na concepção do papel do Estado: do Welfare State para o Estado Concorrencial. Esse contexto revela um descompasso em relação àquelas mudanças que, em boa parte do setor privado, fizeram organizações e indivíduos caminharem para relações de trabalho, com contrato transacional de curto prazo e focado no interesse das partes (Arthur, 1994; Baruch; 2004; Hall \& Moss, 1998). Por outro lado, à medida em que no setor público predominam a regulamentação e os mecanismos burocráticos, o cenário é mais propício para a disseminação do contrato relacional, voltado para a segurança e a estabilidade. Esse contexto tem como possível implicação o surgimento de ambiguidades envolvendo pessoas influenciadas por aquelas mudanças (associadas ao contrato transacional), mas que atuam em instituições públicas (mais propícias ao contrato relacional).

Motivado por esse cenário, delineou-se o presente artigo com o objetivo de compreender como são construídos os processos pessoais de carreira de servidores com carreiras técnicas de nível superior no setor público, frente às diferentes perspectivas articuladas no contexto social contemporâneo.

Para desenvolver essa discussão, no próximo tópico, são tratadas as proposições sobre carreiras. Em seguida, elas são confrontadas com aspectos que envolvem a gestão de pessoas no setor público. As contribuições teóricas articuladas são então utilizadas para definir aspectos teóricos e metodológicos adotados na coleta e na análise dos dados (Análise do Conteúdo), em uma pesquisa de campo qualitativa voltada para o objetivo proposto. Por fim, a partir dos confrontos teóricos e empíricos realizados na análise dos dados, são apresentadas as considerações finais do artigo, voltadas para a constatação da existência de dois tipos básicos de carreira no contexto investigado: o funcionário público típico, inserido na ótica relacional; e o burocrata proteano, um híbrido entre a lógica do proteano do contexto privado e a lógica do setor público.

\section{Proposições sobre Carreiras}

De acordo com Chanlat (1995), pode-se observar a existência de dois modelos de carreira: tradicional e moderno. O primeiro é marcado pela supremacia masculina e das classes dominantes, com o emprego sustentado pela estabilidade e pela progressão vertical. O modelo moderno, marcado pelo ingresso mais acentuado de mulheres e membros de grupos sociais variados no mercado de trabalho, passa a ser caracterizado pela progressão descontínua e pela instabilidade funcional (Balassiano, Ventura, \& Fontes, 2004). 
De acordo com o modelo tradicional, a expectativa das pessoas consistia em trabalhar para a mesma organização ao longo da vida, e o sucesso era atrelado à ascensão de cargos dentro da hierarquia organizacional (Arthur, 1994; Baruch, 2004; Coelho, 2006; Dutra, 1992). Nessa ótica, a carreira pertencia à empresa, visto que era ela quem a gerenciava (Balassiano et al., 2004), e demandava "um ajustamento do indivíduo a uma ocupação escolhida ou à imagem que dela possuía" (Kilimnik, Castilho, \& Sant Anna, 2004, p. 2).

O modelo moderno de carreira é marcado por transformações ocorridas na sociedade contemporânea, que levaram ao surgimento de cinco paradoxos: a demanda cada vez menor por empregos estáveis e bem remunerados; a predominância de preocupações financeiras e de curto prazo; o declínio da ética e dos valores do trabalho; a crise dos sistemas educacionais e de formação; e o encurtamento do horizonte profissional (Chanlat, 1996). As transformações que sustentam esses paradoxos envolvem as "mudanças da economia, a expansão dos mercados, o avanço da tecnologia e a alta densidade demográfica" (Coelho, 2006, p. 94). Diante de tais transformações, as organizações mais competitivas são as que melhor conseguiram articular o conhecimento e a informação, ampliando suas fronteiras.

À medida que as organizações tornaram-se sem fronteiras, as carreiras as seguiram (Lacombe \& Chu, 2006), representando um olhar alternativo sobre o emprego estável e a carreira estritamente organizacional. Na carreira sem fronteira, a trajetória do indivíduo não se vincula a uma organização, mas às suas próprias escolhas e interesses. A crença no paternalismo organizacional dá lugar à busca do autodesenvolvimento, visando à empregabilidade. Esse modelo "pressupõe uma alta identidade com o trabalho, autonomia e mobilidade profissional" (Coelho, 2006, p. 106).

Ao exercerem tal gerenciamento, os profissionais passam a traçar estratégias de desenvolvimento profissional, o que promove a chamada carreira inteligente. Um tipo de carreira na qual se pressupõe que as pessoas devem construir competências para se adaptarem às exigências atuais e abrir portas para oportunidades futuras (Arthur, Claman, DeFillippi, \& Adams, 1995).

Nessa lógica de carreira, há uma mudança na figura do contrato psicológico que regula o relacionamento entre organizações e pessoas. $\mathrm{O}$ contrato de trabalho passa de relacional - marcado por promessas implícitas de estabilidade e segurança no longo prazo - para o transacional - no qual as expectativas das pessoas e das organizações são explicitamente declaradas e estabelecidas em um horizonte dinâmico, de curto prazo (Hall \& Moss, 1998; Schein, 1996; Thiry-Cherques, 2006).

O contrato relacional tradicional "refletia as expectativas mútuas para a relação de trabalho e assegurava a estabilidade do vínculo em troca da dedicação aos objetivos organizacionais" (Martins, 2006, p. 82). Já no contrato transacional, as trocas são utilitárias com interesses negociados explicitamente entre organizações e indivíduos. Do ponto de vista da organização, a principal alteração com o novo contrato é a transformação da oferta de trabalho seguro, que dá lugar a oportunidades de desenvolvimento. Na ótica do indivíduo, encerra-se o compromisso com a organização e inicia-se o compromisso, sobretudo, com a própria carreira (Baruch, 2004; Hall \& Moss, 1998; Motta, 2006; Scheible \& Bastos, 2006) e as maneiras de articulá-la no contexto social mais amplo.

Nesse contexto contemporâneo transacional, Hall e Moss (1998) destacam características do que foi chamado de carreira proteana. O termo proteana se refere ao deus Proteu, que, conforme a mitologia grega, muda sua forma de acordo com a sua vontade. Ao usar o termo, os autores fazem uma analogia às pessoas na lógica transacional, que gerenciam sua própria carreira escolhendo as formas que querem assumir de tempos em tempos em dado contexto, no lugar de deixar que uma organização o faça (Hall \& Moss, 1998).

Ao reconhecer a existência dessa ótica, a análise de um processo pessoal de carreira na contemporaneidade deve considerar o contexto mais amplo no qual a organização e a pessoa se inserem. No caso do setor público brasileiro, foco deste artigo, o contexto da gestão de pessoas é 
permeado pela burocratização, o que promove tanto limitações, quanto oportunidades na articulação das carreiras, que serão discutidas a seguir.

\section{Gestão de Pessoas no Setor Público}

Segundo Saravia (2006), a maneira pela qual os governos organizam os sistemas de trabalho de seus servidores públicos permite agrupá-los em dois sistemas: o sistema de emprego, em que o funcionário é recrutado para um posto, determinando o cargo e as tarefas específicas que este irá desempenhar; e o sistema de carreira, no qual o funcionário é recrutado para um corpo, ou organização, neste caso tendo mais perspectivas para seu desenvolvimento profissional dentro da organização pública. No Brasil, embora vigore o sistema de carreira, este é estruturado em cargos e suas descrições, de modo a legitimar uma estrutura burocrática e não a promover e estimular o desenvolvimento dos indivíduos (Salles \& Nogueira, 2006), pois limita a progressão em termos verticais e a mobilidade dos servidores entre cargos da mesma carreira (Bresser-Pereira, 1996; Saravia, 2006).

Isso fica claro ao se observar que, a partir da Constituição de 1988, o desenvolvimento do indivíduo dentro do quadro do serviço público está limitado às progressões específicas previstas para um cargo ou função. Para progredir entre cargos, o indivíduo necessita novamente de prestar concurso público, uma vez que a estrutura não permite a seleção interna de pessoas (Bresser-Pereira, 1996; Paulista, 2004; Salles \& Nogueira, 2006). Com possibilidades restritas de progressão, os servidores tendem a vivenciar a estagnação de suas carreiras (Salles \& Nogueira, 2006). Segundo Paulista (2004), tal estagnação decorre do fato de os cargos de chefia, direção e assessoramento serem tradicionalmente ocupados por indivíduos recrutados externamente ao serviço público, gerando, nos servidores efetivos, uma desmotivação quanto ao reconhecimento de suas competências.

Deve ficar claro que esse contexto tem como origem uma legislação voltada, supostamente, para estruturar as carreiras públicas no Brasil de modo a valorizar a meritocracia e combater as práticas do nepotismo e do fisiologismo na gestão pública (Secchi, 2009). Contudo, as contradições entre a cultura e a legislação brasileira apenas ampliaram a ambiguidade na gestão de pessoal do setor público (Lemos, 2006; Salles \& Nogueira, 2006). Corroborando com esse entendimento, Kerr (2006) e Matias-Pereira (2008) observam que no Brasil formou-se um sistema de carreiras públicas híbrido, que, por um lado, apresenta características burocráticas, e, por outro, convive com cargos de livre provimento.

O fato de existir esse hibridismo não representa em si um problema. Entretanto, ele faz parte de um processo problemático e mais amplo no setor público, no qual são omitidas medidas que, segundo Ferreira (1996), contribuiriam para a renovação da gestão de pessoas no setor, tais como: um maior incentivo à capacitação e ao desenvolvimento e a revisão dos critérios de remuneração e de avaliação de desempenho no setor público. A discussão desses aspectos exige reconhecer a existência de iniciativas que buscam um enfoque estratégico e certa renovação da gestão de pessoas no serviço público, como o Decreto $\mathrm{n}^{\circ}$. 5.707 de 2006, que rege a política de capacitação e desenvolvimento de pessoas em nível federal.

Entretanto, na prática, tais iniciativas esbarram em limites legais, que permitem questionar sua efetividade, na medida em que não estão integradas com outras ações indispensáveis. Um exemplo disso envolve a discussão do aspecto remuneração. Os dispositivos legais e negociais existentes fizeram com que o setor público, em comparação com o privado, oferecesse melhor remuneração aos seus funcionários de nível operacional e deixasse a desejar na remuneração de cargos de nível superior e executivo (Bresser-Pereira, 1996; Gustafsson, 1998). No Japão, por exemplo, os salários dos servidores públicos são corrigidos anualmente, com base na variação da remuneração paga pelas empresas privadas, de modo a evitar discrepância entre os salários de trabalhadores de ambos os setores (Ikari, 1998; Koga, 2007). 
Supostamente, capacitar um funcionário sem avaliá-lo de acordo com essa nova condição em relação ao mercado de trabalho e não remunerá-lo de maneira coerente pode levar a comportamentos em desacordo com a proposta de contribuir para o serviço público por meio da capacitação. Por exemplo, o funcionário pode se utilizar da nova capacitação para buscar uma colocação profissional em outra organização, inclusive no setor privado. Por outro lado, a legislação também oferece espaço para o servidor público se negar a ser capacitado, protegido pela estabilidade. Apesar da estabilidade ter seu aspecto positivo, enquanto um meio para proteger os servidores e o Estado contra ordens arbitrárias dos governantes (Gasparini, 2007), segundo Bresser-Pereira (1996), ela também conferiu ao serviço público uma maior ineficiência, gerada pela desmotivação e pela desqualificação dos servidores.

A despeito desses aspectos, e em parte por eles, o serviço público no Brasil se constituiu no porto seguro, em que, mesmo com poucas oportunidades de desenvolvimento e perspectivas de progresso profissional (Bresser-Pereira, 1996; Saravia, 2006), era atrativo pela estabilidade em tempos de incerteza (Salles \& Nogueira, 2006). Já no contexto privado, foram justamente essas incertezas que levaram as pessoas a enxergarem a falácia do contrato relacional e a não confirmação da estabilidade implícita. As mudanças ocorridas no cenário econômico, político e institucional das sociedades capitalistas apresentaram dinâmicas de crescimentos e crises com manifestações diversas, como as fusões e aquisições organizacionais, seguidas de contratações e ou demissões de trabalhadores. Isso gerou uma instabilidade e uma incerteza sem precedentes, o que também levou os profissionais a enfrentarem novos arranjos de trabalho, novas configurações de carreiras e alterações nessas relações (Arthur, 1994; Arthur et al.,1995; Baruch, 2004; Hall \& Moss, 1998; Scheible \& Bastos, 2006).

No Brasil, o contraste entre o contexto público e essa lógica que, aos poucos, dissemina-se no setor privado, ficou mais evidente com as privatizações ocorridas nos anos de 1990. Elas revelaram que os servidores públicos estavam com suas carreiras estagnadas, desconsiderando as possibilidades de mudanças nas organizações públicas às quais pertenciam (Soares \& Sestren, 2007), bem como depositando nessas organizações todas as suas perspectivas profissionais (Laegreid, 1998).

Foi nesse cenário que os esforços de flexibilização foram empreendidos no Brasil por intermédio da Reforma Gerencial de 1995. Supostamente, a flexibilização dos sistemas de emprego no setor público visava torná-los mais adaptáveis às exigências externas e conduzi-los a uma gestão mais orientada para resultados (Saravia, 2006). Na prática, como observa Carvalho (1997), tal flexibilização acarretou uma degradação das funções e condições do trabalhador no setor, aumentando o número de trabalhadores com contratos temporários ou subcontratados por meio de terceirizações via licitação. $\mathrm{O}$ autor destaca que, na prática, o efeito foi o pagamento de menores salários a esses trabalhadores, a oferta de menos benefícios e, com a falta de um controle e de uma avaliação adequados, a baixa qualidade de serviços e condições de trabalho. Ocorreu o que poderia se chamar de precarização do trabalhador privado no setor público.

A gestão mais flexível alcançada dessa maneira manteve boa parte das características burocráticas do sistema de carreiras do setor público brasileiro. Entre outros aspectos, o mais destacado foi a ampla inserção, pela via de uma espécie de terceirização, de um trabalhador celetista, que passou a conviver com os já conhecidos instrumentos inadequados para avaliar e desenvolver pessoas, em conjunto com os estatutários. Isso ocorreu, pois as mudanças propostas pela reforma representaram uma importação parcial de tecnologias de gestão do setor privado, em muitos casos sem considerar as peculiaridades inerentes à gestão pública (Fudge, 1998; Secchi, 2009; Siqueira \& Mendes, 2009), bem como ignorando alguns de seus problemas centrais e mais polêmicos, já citados, e que gerariam grandes custos políticos para serem tratados de maneira efetiva.

Nesse cenário, era de se esperar que ocorresse uma acomodação dos servidores públicos; entretanto, neste artigo, articula-se uma reflexão que se opõe a essa ideia. Defende-se o entendimento de que o fenômeno do desenvolvimento das carreiras sem fronteiras na sociedade, destacado por Arthur (1994) desde a década de 1990, envolve, de alguma maneira, os servidores públicos. Eles têm contato com essa lógica por viverem em sociedade, dessa maneira existe a possibilidade de essa mesma lógica interferir na maneira como os servidores articulam suas carreiras. 
Neste artigo, ao se investigar essa possibilidade, concordando-se com Bendassolli (2009) e Chanlat (1995), assume-se que as carreiras recebem impactos das mudanças na sociedade. No caso do Brasil, como revela Alves (2011), o crescimento econômico e as mudanças no mercado de trabalho ao longo do ano 2000 são evidentes, marcando o período pela queda do desemprego e do emprego informal. Na medida em que o mercado de trabalho no setor privado se amplia, entende-se que também surgem alternativas ao emprego público no setor privado. Com base nesse entendimento, defende-se que os profissionais, mesmo estando no serviço público, já podem estar planejando e articulando suas carreiras, nem sempre vinculadas à estrutura de crescimento intraorganizacional (Arthur, 1994).

Portanto, propõe-se que, assim como está ocorrendo no setor privado, a lógica proteana pode se manifestar no setor público, na medida em que o servidor vai além do comportamento padrão, formalmente esperado dele enquanto agente público com um papel a desempenhar. Informalmente, o servidor pode usar a própria estrutura pública e os benefícios por ela oferecidos para o alcance de objetivos pessoais, em outras organizações (Oliveira, 2007). Defende-se que esse uso teria o potencial de refletir em planos de carreiras pessoais muito além do cargo tradicional do serviço público, em uma lógica mais proteana. A referida proposição baseia o objetivo tratado neste artigo. Para desenvolvê-lo, as articulações teóricas realizadas até aqui serão confrontadas com dados empíricos obtidos em uma pesquisa de campo realizada em uma instituição pública.

\section{Aspectos Metodológicos}

Para a consecução dos objetivos propostos, optou-se pela realização de um estudo de caso descritivo em um recorte qualitativo (Vieira, 2006), pelo entendimento de que essas escolhas possibilitam as condições para uma abordagem com um nível de profundidade adequado ao objetivo proposto.

Os dados empíricos foram coletados ao longo do ano de 2010. Como técnica de coleta de dados, foi empregada a entrevista direta, baseada em um roteiro semiestruturado, com o intuito de compreender processos e crenças do entrevistado, a partir de um contato direto que possibilita interação entre entrevistado e pesquisador, e potencializa a coleta de dados (Creswell, 2007).

Essa coleta foi realizada em uma sala de reuniões específica, localizada na própria secretaria que foi o locus da pesquisa, uma sala afastada das outras, fechada e silenciosa, destinada apenas às entrevistas nos dias marcados. Ela foi escolhida justamente por apresentar essas características, necessárias para minimizar a possibilidade de o entrevistado se sentir constrangido pela falta de privacidade, ou perder o foco da discussão, em virtude de possíveis distrações, tais como ruídos ou movimentações de pessoas.

Outra preocupação quanto à coleta de dados foi com o tempo das entrevistas, pois, caso se alongassem demasiadamente, poderiam gerar um grau de desgaste nos respondentes que prejudicaria sua capacidade ou disposição para colaborar com a pesquisa. Com base nessa preocupação, o tempo médio das entrevistas realizadas foi em torno de 40 minutos, ao longo dos quais nenhum respondente demonstrou um grau de desgaste excessivo.

A escolha dos sujeitos de pesquisa foi delimitada aos profissionais de carreiras técnicas de nível superior ligados a uma Secretaria de Estado que trata da gestão de recursos humanos em um estado brasileiro. A secretaria em questão foi escolhida por contar com profissionais de diversas áreas de formação. Essa escolha se justifica pelos seguintes motivos: (a) a dinâmica das configurações de carreiras atuais se mostra oportuna para os grupos com maior qualificação, não sendo ainda realidade para a maioria dos profissionais de nível operacional (Arthur et al., 1995); (b) a intenção de não ater este estudo às influências de um grupo com formação profissional específica (contadores, engenheiros, economistas...), pois o foco da discussão é o contexto do setor público e não o contexto de formação 
de um grupo profissional; (c) os profissionais escolhidos são ligados permanentemente ao serviço público, com carga horária de trabalho semanal de quarenta horas, diferindo-se de profissionais de outras áreas, como saúde, educação e assistência social, para os quais o serviço público não se constitui parte única da vida profissional; (d) são servidores efetivos, estáveis e estatutários, diretamente envolvidos pelos aspectos característicos do vínculo típico do servidor público no Brasil, focados neste artigo: estabilidade e efetividade no cargo e promoções por senioridade, na maioria dos casos com poucas implicações meritocráticas. Como na lógica proteana de carreira há certo dinamismo nos vínculos profissionais (Hall \& Moss, 1998), optou-se por investigar tanto os atuais servidores quanto os ex-servidores que se desvincularam por iniciativa própria e se disponibilizaram a participar do presente estudo.

No tocante aos servidores atuais, após a autorização da gerência da Secretaria de Estado para realização das entrevistas nas dependências da mesma, os sujeitos foram convidados a participar pelo envio de um e-mail de apresentação com os objetivos da pesquisa, informando dias, horários e a sala onde a pesquisa iria ocorrer. Dessa forma, foram entrevistados os servidores que compareceram ao local definido, atendendo ao convite, pelo interesse e disponibilidade para responder à entrevista.

No tocante aos ex-servidores, a Secretaria disponibilizou uma lista com os nomes e telefones dos profissionais que pediram exoneração do cargo público e os mesmos foram abordados por contato telefônico, tendo os objetivos da entrevista apresentados e, sendo os mesmos convidados a participar. Uma vez que o ex-servidor aceitou participar, foi marcado o momento da entrevista com ele.

Portanto, a amostragem em questão se caracteriza como não probabilística, intencional e limitada à participação dos informantes que aceitaram participar da pesquisa. A opção por essa amostragem contribuiu para a viabilidade da pesquisa. Entretanto, ela também remete à limitação da inadequação de se fazer generalizações em termos de populações ou universos a partir da amostragem em questão, pois oferece legitimidade apenas para que sejam articuladas proposições teóricas baseadas no caso estudado (Bryman, 1988; Yin, 1994).

Outro ponto a destacar, segundo McClintock, Brannon e Maynard-Moody (1983), é o fato desse tipo de escolha dos informantes ser caracterizado por algumas dificuldades básicas: selecionar aqueles que efetivamente tenham conhecimento sobre o tema a ser investigado; saber se o que eles informaram realmente reflete a realidade; e controlar os vieses oriundos desses informantes. Segundo os autores, aspectos como motivações ocultas, percepções incompletas e/ou mentiras por parte dos respondentes têm o potencial de direcionar os dados de uma maneira que pode fugir do controle do pesquisador. Como alternativa, os autores defendem que tais vieses sejam minimizados ao se atentar para os referidos aspectos ao longo da definição do grupo final dos sujeitos de pesquisa e da análise de suas manifestações.

Com base nessas preocupações e nos critérios apresentados, o grupo final dos sujeitos de pesquisa teve a seguinte configuração:

1. Quinze servidores da Secretaria de Estado (SP): indivíduos ocupantes de cargo efetivo, com estabilidade adquirida, ligados a carreiras técnicas de nível superior;

2. Cinco ex-servidores da Secretaria de Estado (ESP): indivíduos que ocupavam cargo efetivo e possuíam estabilidade, também ocupantes de carreiras técnicas superiores e que se desligaram por vontade própria do serviço público, por um período de até cinco anos.

A Tabela 1, a seguir, descreve parte do perfil desses respondentes, dentro de um limite de detalhamento que mantém o sigilo da identidade dos mesmos. Ou seja, as informações foram agrupadas ou omitidas para não ser possível identificar um indivíduo isolado dentro do contexto profissional no qual atua ou atuou. 
Tabela 1

Características dos Respondentes

\begin{tabular}{ccccc}
\hline Código & Faixa de Idade & Sexo & Cargo & Formação \\
\hline SP1 & $25-35$ & F & Analista de Gestão & Contador \\
SP2 & $36-45$ & M & Analista de Políticas Públicas & Economista \\
SP3 & $25-35$ & F & Analista de Gestão & Advogado \\
SP4 & $25-35$ & F & Analista de Gestão & Administrador \\
SP5 & $25-35$ & M & Analista de Gestão & Administrador \\
SP6 & $25-35$ & M & Analista de Gestão & Administrador \\
SP7 & $36-45$ & F & Analista de Políticas Públicas & Advogado \\
SP8 & $25-35$ & M & Analista de Políticas Públicas & Contador \\
SP9 & $25-35$ & F & Analista de Políticas Públicas & Contador \\
SP10 & $36-45$ & M & Analista de RH & Psicólogo \\
SP11 & $36-45$ & M & Analista de RH & Advogado \\
SP12 & $36-45$ & F & Analista de RH & Administrador \\
SP13 & $25-35$ & M & Analista de Gestão & Contador \\
SP14 & $25-35$ & F & Analista de Políticas Públicas & Economista \\
SP15 & $36-45$ & F & Analista de RH & Psicólogo \\
ESP1 & $36-45$ & F & Analista de gestão & Administradora \\
ESP2 & $25-35$ & M & Analista de gestão & Contador \\
ESP3 & $36-45$ & M & Analista de políticas públicas & Advogado \\
ESP4 & $36-45$ & F & Analista de políticas públicas & Administradora \\
ESP5 & $36-45$ & M & Analista de gestão & Contador \\
\hline
\end{tabular}

Nota. Fonte: dados da pesquisa. Legenda: F - feminino; M - masculino; SP - servidores da Secretaria de Estado; ESP - exservidores da Secretaria de Estado.

As entrevistas realizadas com esses sujeitos foram gravadas em equipamento de áudio, e, posteriormente, transcritas na íntegra. O tratamento dos dados foi feito a partir da Análise de Conteúdo em uma abordagem temática (Bardin, 1979; Minayo, 2007). Ou seja, as entrevistas foram categorizadas em uma grade temática de conteúdos. A grade de categorias adotada foi a mista (Vergara, 2008), na qual parte das categorias é definida a priori, com base nas articulações teóricas, e outra parte é definida a partir dos próprios dados coletados.

As categorias de análise definidas a priori foram as seguintes: experiências profissionais; ingresso no serviço público; mudanças na estrutura pública; relação com a mudança; remuneração/benefícios; aspectos positivos e negativos do trabalho no setor público; qualificação profissional e oportunidade de desenvolvimento profissional; pressões e tensões do trabalho no serviço público; perspectivas futuras dos servidores públicos; sucesso profissional; fatores ligados à saída do setor público; diferenças nas perspectivas de carreiras antes e depois de sair do serviço público. Com base nos dados coletados, foi acrescentada a seguinte categoria: mudança de visão sobre a carreira. Em conjunto, elas permitiram o desenvolvimento da análise apresentada a seguir. Na análise, para preservar o anonimato dos respondentes, os fragmentos de entrevistas apresentados são identificados apenas pelas letras SP, no caso dos servidores, e ESP, no caso de ex-servidores, seguidas de um número. 


\section{A Gestão e as Carreiras no Setor Público}

Os dados coletados evidenciaram que parte das características advogadas como adequadas para o desenvolvimento de diferentes tipos de carreira estavam presentes no contexto público investigado. Entretanto, tais características não surgiram nas manifestações dos respondentes como associadas diretamente ao desenvolvimento da carreira, mas apenas como uma fonte de melhoria do desempenho das pessoas na organização, sem, necessariamente, ter implicações em suas carreiras.

Isso fica claro no fragmento um, apresentado a seguir, quando o entrevistado aponta as mudanças provocadas pelos princípios da Administração Pública Gerencial como positivas nas organizações públicas. Os princípios estabelecidos pelo referido modelo de gestão pública, como, por exemplo, foco no resultado e no usuário, desenvolvimento gerencial e profissionalização (Ayres, 2006; Bresser-Pereira, 2008; Corrêa, 2007), são analisados apenas como elementos que promovem melhor desempenho das organizações públicas na atualidade, sem mencionar benefício ou prejuízo para as carreiras dos envolvidos.

\footnotetext{
"Eu vejo que teve uma melhora muito grande em questões de governo nos últimos anos; foram passos essenciais de mudanças que a gente pode perceber, a gente ouvia falar, mas agora que está aqui, a gente vê que muita coisa mudou, hoje você tem que dar resultado aqui dentro, cada servidor é olhado como responsável pelo o que acontece, ele é um gerente do Estado, e assim, as coisas podem acontecer, não é como antes" (SP 11)
}

Isso ocorre mesmo quando os respondentes criticam o foco desse desempenho na administração e não nos resultados para a sociedade, essa ênfase na administração não surgiu associada a contribuições para a gestão da carreira dentro de uma ótica tradicional. Cabe esclarecer, como destacam Misoczky e Vieira (2001) e Kuin (1968), que essa ambiguidade sobre desempenho no setor público gira em torno de dois polos: desempenho para a população (usuários) ou desempenho para o governo (governantes). Como se observa a seguir.

“O setor público, pelo que eu vejo, tem muito ainda que melhorar... Ele acaba sendo voltado para a administração. Deveria ser mais voltado para a população porque, na verdade, a gente sabe que é um interesse primário do governo e você vê que às vezes o interesse secundário que é da administração acaba prevalecendo e triunfa sobre o interesse da coletividade" (SP 10).

Ou seja, mesmo com o foco na administração, as questões relativas à administração da carreira seguem silenciadas. Por outro lado, de maneira contraditória ao movimento gerencial e, conforme discutido por Siqueira e Mendes (2009), Fudge (1998) e Secchi (2009), as ideias gerenciais esbarram, na prática, em elementos que são peculiares ao serviço público e com o potencial de impactar nas carreiras: as ingerências políticas, como evidenciaram os servidores públicos sete e onze:

“a grande desvantagem do serviço público é o jogo político” (SP 07).

“Outra questão é a influência política, onde não deveria haver a pressão política no setor, isso acaba atrapalhando as pessoas na profissionalização de algumas áreas” (SP 11).

Dessa forma, como observou Junquilho (2004), o servidor público transita entre o exigido e o possível, e precisa adaptar as premissas da gestão pública gerencial a um contexto permeado por elementos políticos. Nessa ótica, uma mudança mais profunda na gestão pública, conforme exposto por Ferreira (1996), exige associar tanto governabilidade quanto governança, o que inclui as questões relativas à carreira, mesmo que em uma lógica tradicional com foco na organização. No caso estudado, observou-se que há vontade e capacidade de implementar mecanismos gerenciais no setor público, contudo, ainda é necessário ampliar os mecanismos legais para fazê-los; a governabilidade necessita ser implementada, de modo que o desempenho possa ser atrativo ao servidor público, como observado no fragmento a seguir: 
"porque pro servidor, pro funcionário prestar um bom serviço... ele precisa ter um retorno disso e o que eu percebo na vida profissional é que não existe equiparação nessa troca: geralmente é exigido mais e não é pago financeiramente ou outros benefícios em troca dessa exigência. Aqui é assim, faz, dá resultado e muito obrigada e isso não prende um bom funcionário, aliás, nem estimula [sic]” (SP 07).

Conforme exposto pelo entrevistado SP 07, o desempenho exigido não é acompanhado de mecanismos de recompensa para tal, que remetam a pessoa a se manter na carreira pública dentro da lógica desse desempenho elevado. Ao mencionar que o que é oferecido "não prende um bom funcionário", o entrevistado dá margem ao entendimento de que o "bom funcionário" vislumbra a possibilidade de sair da carreira pública para articular seu desempenho em outro contexto. Tal manifestação remete a um dinamismo nos vínculos profissionais mesmo dentre os servidores públicos que pode, pelo menos parcialmente, ser associado ao entendimento de carreira proteana de Hall e Moss (1998).

\section{Ambiguidades na lógica tradicional de carreira na Secretaria de Estado investigada}

O questionamento de características típicas da carreira tradicional no setor público, baseadas no contrato relacional (Martins, 2006), evidenciam certa aproximação de alguns servidores com a lógica proteana na Secretaria de Estado investigada. As manifestações desses respondentes se voltam, por exemplo, para a crítica à progressão por senioridade, como não servindo de estímulo para pessoas que não estão dispostas a esperar o tempo passar para ter seu desempenho reconhecido (Bresser-Pereira, 1996), conforme mostra o fragmento seis.

"muitas pessoas boas têm saído... e eu sou um dos pretendentes a deixar o cargo em questão de dois anos, no máximo. Eu não pretendo estar aqui com esse salário e sei que não podem fazer nada, então, por mais que reconheçam que sou um bom funcionário, que ajudo a secretaria no que faço, não têm como me remunerarem melhor, então eu quero sair sim" (SP 08).

A tendência do setor público oferecer remunerações menores aos servidores de nível superior quando comparado com o setor privado (Bresser-Pereira, 1996; Gustafsson, 1998) se confirma no caso do respondente em questão. Especificamente na secretaria investigada, que conta apenas com servidores de nível superior, isso é destacado pelos entrevistados como um fator negativo:

"Analisando a minha formação e o meu trabalho... Eu comparo a iniciativa pública com a iniciativa privada: é a mesma carga horária, mesmas atividades e o cliente da área pública é mais importante do que o cliente da área privada e, no entanto, a remuneração é a metade. A remuneração é um ponto negativo do setor público" (SP 07).

Outro ponto apresentado pelos entrevistados, em relação à secretaria investigada, refere-se à confusa mistura de meritocracia e aspectos pessoais no desenvolvimento das carreiras. De maneira convergente com o que foi observado por Kerr (2006) e Matias-Pereira (2008), os servidores apontam que, para chegarem aos cargos de chefia, é necessária uma articulação política e pessoal, conforme relatado a seguir:

"Não tenho esta possibilidade [de chegar a cargo de chefia] porque cargo maior é tudo cargo comissionado e pra você ser indicado é complicado. Assim, o máximo que você cresce é pouca coisa, agora para cargo maior não tem possibilidade de crescimento [sic]” (SP 12).

Dessa forma, a gestão do mérito na secretaria investigada vai até o ponto em que encontra as vontades pessoais. Como demonstrado por Barbosa (1996), embora tenhamos legalmente a meritocracia na gestão pública brasileira, carecemos, enquanto país, de tê-la culturalmente, uma vez que o acesso aos cargos de chefia é, em muitos casos, atrelado a fatores exógenos ao desempenho do servidor. Na investigação em questão, essa característica foi observada permeando o modelo tradicional de carreira pública e o afastando do modelo tradicional do setor privado. Por sua vez, em termos da lógica proteana, temos mais um elemento que legitima certo direcionamento a ele, dentro do contexto público. Isso ocorre pois essas articulações políticas associadas à carreira têm o potencial de remeter a uma visão, mesmo que distorcida, de que cabe ao servidor público articular seus interesses 
de carreira, mesmo que para além da meritocracia. Esse último aspecto foge da suposta visão proteana de carreira mais desenvolvida por Hall e Moss (1998), indicando a possibilidade da existência de um híbrido, o burocrata proteano.

Para esse híbrido, um possível mau desempenho, que poderia ser um problema na lógica do setor privado, na lógica pública pode nem mesmo ser interpretado como mau desempenho. Há espaço, segundo Barbosa (1996), para que um mau desempenho seja considerado apenas uma falha do sistema de avaliação, que deve ser corrigido a partir de articulações pessoais ocultadas por uma formalidade meritocrática. Segundo a autora, o formalismo meritocrático é permeado por normas e discursos que, comumente, não são efetivamente aplicados no cotidiano das organizações públicas brasileiras. Essa pessoalidade fere a meritocracia, ao mesmo tempo em que busca se ocultar na formalidade meritocrática, cabendo ao servidor público articular seus interesses dentro dessa ambiguidade. No caso investigado, observou-se uma maneira de fazer isso: posicionar o seu desempenho e o dos colegas de trabalho como bom, sem apresentar uma maneira clara para referenciar essa avaliação e silenciar sobre o mau desempenho.

Conforme evidenciado nos fragmentos de entrevistas apresentados, o bom desempenho foi frequentemente manifestado pelos respondentes como algo que faz parte da vida deles, mas o mau desempenho é algo silenciado por eles, como se não existisse na secretaria investigada. Entretanto, onde existem grupos de pessoas trabalhando, tende a ocorrer diferentes níveis de desempenho, mas sem uma referência para avaliação, qualquer nível de desempenho pode ser atribuído a todos, como o nível bom manifestado pelos respondentes.

Ou seja, no caso do híbrido burocrata proteano, a lógica proteana tradicional, essencialmente meritocrática, reveste-se do relativismo do mérito, no qual o bom ou o mau desempenho são relativos à capacidade do burocrata articular essa interpretação no seu contexto profissional. Como consequência, para o burocrata proteano, o desempenho não se apresenta, necessariamente, como um obstáculo para que ele gerencie sua carreira, pois pode ser interpretado como adequado por ele e seus pares, até mesmo em oposição a sistemas de avaliação ou gestores que indiquem o contrário (Barbosa, 1996). Claro que, com o tempo, caso saia do setor público, ele pode ou não ter sucesso em continuar a articular essa relativização do mérito.

Outro aspecto do referido hibridismo, observado na secretaria investigada, foi manifestado por quase todos os respondentes: a estabilidade é considerada o principal fator que levou os profissionais entrevistados a ingressarem no serviço público:

"O que me levou a entrar na rede pública foi a estabilidade" (ESP 1).

"Foi o equilíbrio, você saber que ninguém pode te tirar aquilo a não ser que gere problemas, mas nesse caso já é diferente" (SP 2).

"Eu só vim pela estabilidade, eu vim pra ganhar metade do que eu ganhava na iniciativa privada; entrei [no serviço público] porque a gente não sabe o futuro, então, de repente hoje tá tudo bem e amanhã não tá e eu sou bem conservadora, então eu prefiro ter um valor menor fixo e saber que eu vou ter pelo resto da vida do que ter de repente um valor alto hoje e amanhã não ser mais aquilo... Preferi a estabilidade ao dinheiro" (SP 07).

Essas manifestações vão ao encontro do entendimento de autores como Bresser-Pereira (1996), Salles e Nogueira (2006) e Paulista (2004), que destacam a estabilidade como o elo chave de atratividade para o ingresso no serviço público. Ela representa um refúgio face às incertezas inerentes ao trabalho contemporâneo (Evans, 1996; Kilimnik et al., 2004). Entretanto, de maneira ambígua, isso também é reconhecido pelos sujeitos da pesquisa como um aspecto relevante que os motiva a replanejar a carreira para além do cargo público que possuem. Para eles, a estabilidade é o porto seguro que, ao mesmo tempo, representa um elemento de frustrações, conforme evidencia o fragmento a seguir: 
“quando você ganha estabilidade, você pensa, nunca mais quero outra coisa, mas aí vê um crescendo aqui, outro ali, e, com o tempo, você analisa que sua vida não andou, você tá parado, aí pra mim chegou a hora que não deu mais" (ESP 2).

Aqui fica claro que a aceitação da estagnação da carreira é vista como o preço pelas vantagens da estabilidade. A oposição a essa estagnação é que leva ao questionamento da estabilidade, e a disposição a se abrir mão dela. Ao conceber essa ideia, o servidor abre espaço para construir sua própria carreira, indo além das limitações típicas da carreira pública, comumente com progressões associadas, na prática, ao tempo no cargo e não ao desempenho da pessoa (Ferreira, 1996; Saravia, 2006). Surge assim uma lógica distinta de carreira, atrelada ao desempenho individual e à busca por novos horizontes profissionais, inclusive, no caso da secretaria investigada, com a utilização do próprio contexto público para isso, como se observa no fragmento a seguir:

"O que me levou, na época, a sair do serviço público foi uma oportunidade melhor de trabalho na rede privada; eu tinha feito vários cursos e estava atualizada profissionalmente e, através de um contato do setor público, eu consegui o trabalho na rede privada; aí foi difícil convencer minha família, porque a estabilidade pesava, mas, mesmo assim, eu larguei tudo e fui pra iniciativa privada, porque a gente estuda pra quê? No serviço público, eu ia morrer fazendo a mesma coisa... Não tinha como crescer” (ESP 1).

Desse modo, no contexto da Secretaria de Estado investigada, observou-se que, mesmo com o setor público atuando sobre os modelos tradicionais de carreira (Chanlat, 1995, 1996), é possível encontrar dentre os servidores manifestações de elementos proteanos de carreira (Hall \& Moss, 1998), mesclados com a lógica pública brasileira.

\section{O burocrata proteano}

Quando os servidores manifestaram o uso da sua atuação na carreira pública para se adequar a seus interesses de carreira no setor privado, ficou clara a aproximação com a lógica proteana, na qual a pessoa muda sua forma conforme o contexto para gerenciar sua carreira (Hall \& Moss, 1998). Isso pode ser observado no trecho do fragmento acima, no qual a ex-servidora ESP 1 relata que "tinha feito vários cursos e estava atualizada profissionalmente e, através de um contato do setor público, eu consegui o trabalho na rede privada". Na análise dos dados como um todo, foi possível evidenciar alguns servidores articulando a estrutura pública para se qualificar, criar uma rede de relacionamentos e identificar os elos que possibilitem construir sua carreira, inclusive fora do contexto público.

Dois exemplos dessa utilização do conhecimento e da rede de relacionamentos ofertados pela organização pública para a busca de novos trabalhos são apresentados nos fragmentos catorze e quinze a seguir:

"O ponto positivo é que eu estou aprendendo tantas coisas que eu tenho a possibilidade de conhecimento, não fico só em um projeto, mas em muitos outros, que estão sendo desenvolvidos pelos nossos colegas dentro do Governo do Estado e fora também. Você conhece pessoas de outras prefeituras, de outros estados, e isso traz o conhecimento do que está acontecendo por aí e, quanto mais capacitado eu for, mais fácil fica para eu conseguir um outro trabalho" (SP 09).

"Eu aprendi muito... Em questões de administração pública, desenvolvimento de pessoas, carreiras... O conhecimento foi muito grande e, até a gente tomar uma decisão, se sai ou continua aqui, esse é um aspecto positivo" (SP 10).

Essas manifestações corroboram com o entendimento de Oliveira (2007) acerca da existência do burocrata alpinista, profissionais que, independente da estabilidade no serviço público, buscam outras oportunidades de carreira, algo pouco mencionado nos estudos sobre carreira no serviço público. No caso deste artigo, os aspectos proteanos identificados em alguns servidores, dentre outros aspectos já discutidos, incluem a lógica do burocrata "alpinista" discutida por Oliveira (2007), articulados de duas maneiras distintas: (a) crescimento pelo uso pessoal dos recursos públicos voltados para aperfeiçoar o serviço público (como evidenciado nos fragmentos catorze e quinze); (b) possibilidade do uso de recursos do cotidiano do trabalho, como as instalações, os equipamentos e o tempo, para se aperfeiçoar por conta própria. Este último pode ser identificado no fragmento dezesseis: 
“Aqui é mais tranquilo e eu posso estudar pra outros concursos... consigo me preparar melhor para buscar outro cargo melhor [sic]" (SP 11).

Dessa forma, pode-se perceber que há, entre os servidores públicos, uma busca por ascensão na carreira por conta própria, inclusive dentro do setor público. Foi recorrente entre os entrevistados, quando perguntados sobre as perspectivas de carreira, que eles estão se preparando para outros concursos, conforme mostrado nos fragmentos dezessete e dezoito:

"Passei no concurso público e pensei: agora estou tranquilo aqui, mas depois a gente vê que quer mais e ainda estou estudando para fazer outra prova" (SP 12).

"Eu estou me especializando na minha área, estou terminando pós-graduação agora, e pretendo fazer mestrado... E passar em outro concurso que me dê uma estrutura melhor" (SP 11).

Assim, os servidores públicos estão construindo suas perspectivas de carreira independentemente da estrutura organizacional à qual pertencem, em alguns casos voltando-se para o contexto privado, e em outros mantendo-se no público. Como propõem diversos autores que têm discutido a temática da carreira na contemporaneidade, como Arthur (1994), Baruch (2004) e Hall e Moss (1998), as organizações influenciam as escolhas profissionais dos indivíduos, mas essas influências nem sempre têm como consequência a defesa dos interesses organizacionais. No contexto público investigado, alguns profissionais são influenciados pela organização até por usarem seus recursos para buscarem outras carreiras, públicas ou privadas, o que vai além dos interesses organizacionais específicos. Ou seja, a partir dessas influências, os servidores podem adotar até perspectivas de carreira que não correspondem às características das organizações às quais pertencem. Dessa forma, mesmo com as organizações públicas atuando sobre as premissas tradicionais de carreira, alguns indivíduos assumem comportamentos mais próximos do novo contrato de trabalhotransacional (Hall \& Moss, 1998).

O conjunto dessas evidências remete ao entendimento de que alguns profissionais do setor público têm rompido com a lógica de carreira da organização à qual pertencem, e estão criando, dentro do setor público, carreiras sem fronteiras vinculadas às suas perspectivas pessoais. Cabe destacar que nem todos os respondentes romperam com a estabilidade, apenas passaram de um cargo para outro e continuam no serviço público, buscando novos trabalhos que melhor satisfaçam suas expectativas individuais, enquanto outros utilizaram as articulações de sua inserção no serviço público justamente para se inserir no contexto privado.

O comportamento dessas pessoas no setor público assemelha-se às características da carreira proteana, pois esses estão comprometidos com seus próprios interesses, adotando um comportamento utilitário em relação às organizações. Podemos observar pelos fragmentos treze e catorze, que os profissionais as usam para buscar conhecimento, saber como, e relacionamentos, ou saber quem (Arthur et al., 1995) para auferir novas oportunidades de trabalho, sejam elas dentro ou fora do setor público. Deve ficar claro que isso não ocorre necessariamente por acaso, como se as oportunidades surgissem inadvertidamente. Há uma clara intencionalidade das pessoas voltadas para identificar oportunidades e (re)construir suas carreiras, como se observa no fragmento dezenove:

"Eu fiz muitos contatos no setor público e aí eu aproveitei um desses contatos que era da rede privada e enviei um currículo. Como estava empregada, eu pude negociar, então foi bem legal, porque eu vi que além de ganhar mais, podia também crescer" (ESP 04).

Como discutido pelos autores que tratam da lógica proteana (Hall \& Moss, 1998, entre outros) em um contexto mais amplo e por Motta (2006) com foco no contexto brasileiro, a lealdade das pessoas com a organização tem se transformado em lealdade para consigo próprias. E isso foi observado entre os servidores e ex-servidores públicos entrevistados. Nesse aspecto, a Administração Pública Gerencial e suas premissas adotadas pelo setor público, incluindo seu foco em formar gerentes pode, de certa forma, ter inadvertidamente influenciado esse processo, o que foi apontado por um servidor e um ex-servidor: 


\begin{abstract}
"Hoje eu me sinto um gerente e isso envolve também ter um comportamento de gerente, então, a gente tem que atuar como os profissionais do setor privado... Eu estou sempre buscando novas coisas, nesse mundo de mudança a gente não pode parar enquanto profissional" (SP 13).
\end{abstract}

"Na verdade, eu acho que a gente foi preparado para isso, eu fiz muitos cursos, principalmente na área de resultados e recursos humanos que estimularam esse lado em mim, de pensar que, se o mundo tá mudando a gente também tem que acompanhar, eu acho que isso me encorajou a sair" (ESP 05).

Nos fragmentos vinte e vinte e um, pode-se perceber que a transposição de técnicas de gestão do setor privado para o público (Siqueira \& Mendes, 2009), de certa maneira, gerou-se uma contradição, sobretudo nas carreiras públicas: a lógica gerencial de resultados do setor privado é acompanhada por uma mobilidade articulada entre organizações e indivíduos, como aponta Motta (2006). No caso das organizações públicas, o discurso de novas competências, mudanças constantes, adaptações e qualificações dos indivíduos (Bresser-Pereira, 2007), não foi acompanhado por mudanças na estrutura pública que ainda tem suas organizações pautadas nas características tradicionais de carreira (Chanlat, 1995). Alguns indivíduos assumiram comportamentos e expectativas dentro de uma estrutura pública vinculada às amarras legais que não permitem responder às demandas por um contrato transacional.

Deve ficar claro que nem todas as organizações privadas respondem a essas demandas, elas podem optar por se manter no contrato relacional. Mas parece certo que a situação do contexto público é mais limitada do que a do privado, para responder às demandas transacionais identificadas na presente análise. Identificou-se um comportamento no qual, apesar da organização pública buscar interferir diretamente nas carreiras das pessoas (Arthur, 1994), essas últimas são capazes de identificar e usar as limitações do contexto público para perverter os planos da organização e usar os próprios recursos desses planos com um propósito: definir sua própria carreira, numa espécie de lógica do burocrata proteano.

\title{
Considerações Finais
}

Ao voltar-se para a compreensão de como são construídos os processos pessoais de carreira de servidores com carreiras técnicas de nível superior no setor público, frente às diferentes perspectivas de carreiras articuladas no contexto social contemporâneo, o objetivo deste artigo permitiu descortinar uma série de ambiguidades. A despeito de alguns autores, como Arthur (1994), destacarem o impacto que as organizações têm sobre a carreira pessoal, no contexto público investigado, formalmente direcionado para práticas relacionadas com o contrato relacional, essas mesmas práticas eram pervertidas por pessoas que as usavam para traçar sua carreira de maneira independente. Nesse contexto, foi possível evidenciar indivíduos gerenciando suas carreiras de maneira autônoma em relação às premissas assumidas pelas organizações públicas, em composições de elementos que caracterizam o que foi aqui chamado de burocrata proteano: um profissional que se utiliza da burocracia pública para ser proteano, observando que os recursos e as limitações dela são articulados nas metamorfoses de carreira, em lógicas as quais ele se utiliza como servidor público para satisfazer suas expectativas individuais de carreira e até pode abrir mão da estabilidade.

A partir desse entendimento, propõe-se um olhar distinto para o tema, reconhecendo que coexistem no setor público profissionais com perspectivas distintas de carreira: (a) uma mais tradicional, baseada na premissa da estabilidade, da durabilidade e da senioridade na carreira (Bendassolli, 2009; Chanlat, 1995, 1996; Dutra, 1992), convergentes com as premissas das organizações públicas; (b) outra mais relacional que, de maneira ambígua, articula elementos da primeira para poder existir, assumindo uma dinâmica com semelhanças em relação às características da chamada carreira proteana (Hall \& Moss, 1998).

Esse entendimento sustenta a relevância deste artigo, com base na proposição de que se inclua, nas análises sobre carreira nos contextos públicos, um olhar sobre essa construção ambígua. Ou seja, propõe-se que os interessados sobre o tema observem construções que vão além do fato das 
organizações públicas manterem suas práticas de recursos humanos focadas nas premissas tradicionais de carreiras (Chanlat, 1995, 1996): seleção por concursos e progressão por senioridade. Nessas construções, as pessoas exercem seu potencial para planejar o desenvolvimento de suas carreiras, baseadas em perspectivas que diferem das intenções de tais práticas no setor público. Entretanto, as pessoas não deixam de articular essas práticas, mas usam-nas em seus interesses próprios, como na opção por fazer concursos públicos sucessivos e usar os recursos de uma instituição pública para estudar para um concurso seguinte.

Outro fator a se destacar nesta discussão refere-se à valorização da estabilidade. A quase totalidade dos profissionais entrevistados manifestou que esse foi o fator chave para sua inserção no contexto público. Mas, depois dessa inserção, um grupo, o dos que foram aqui chamados de burocratas proteanos, indicou assumir perspectivas de carreira que incluem a busca constante por conhecimentos, relações, recursos e novos trabalhos, e, apesar de parte dele fazer isso sem romper com aquela segurança (os burocratas proteanos no setor público), outra parte até isso aceita (os burocratas proteanos no setor privado). Em comum, os burocratas proteanos articulam sua inserção pública para prover as transformações de carreira. Mas o burocrata proteano do setor privado, ao sair de sua inserção pública, está sujeito às pressões sofridas pela insegurança do proteano típico (Hall \& Moss, 1998). De maneira distinta, o burocrata proteano do setor público não sofre essas pressões da carreira moderna, pois permanece sob a estabilidade de diversos cargos públicos, ao mesmo tempo em que consegue articular certa autonomia e independência no gerenciamento de sua trajetória profissional.

Por fim, como contribuição final, sugere-se ampliar a discussão de um aspecto evidenciado a partir da identificação das concepções de carreira pública tradicional, do burocrata proteano no setor privado e do burocrata proteano no setor público: as implicações de cada uma das três no desempenho dos profissionais dentro e fora das organizações públicas. Uma investigação que envolva aspectos éticos e morais, bem como os ganhos e prejuízos potenciais das pessoas, das empresas privadas e públicas nas quais atuam e da sociedade como um todo.

\section{Referências}

Alves, G. (2011). A nova morfologia do trabalho no Brasil na década de 2000. Perspectivas, 39(1), 155-177.

Arthur, M. B. (1994). The boundaryless career: a new perspective for organizational inquiry. Journal of Organizational Behavior, 15(4), 295-306. doi: 10.1002/job.4030150402

Arthur, M. B., Claman, P. H., DeFillippi, R. J., \& Adams, J. (1995). Intelligent enterprise, intelligent career. The Academy of Management Executive, 9(4), 7-20. doi: 10.5465/AME.1995.9512032185

Ayres, C. B. (2006). A administração pública brasileira e as vicissitudes do paradigma de gestão gerencial. Sociologia, Problemas e Práticas, (51), 29-52. Recuperado de http://www.scielo.oces.mctes.pt/pdf/spp/n51/n51a03.pdf

Balassiano, M., Ventura, E. C. F., \& Fontes, J. R., Filho (2004). Carreiras e cidades: existiria um melhor lugar para se fazer carreira? Revista de Administração Contemporânea, 8(3), 99-116. doi: $10.1590 /$ S1415-65552004000300006

Barbosa, L. (1996). Meritocracia e desempenho: o que é desempenho no Brasil? Revista do Serviço Público, 120(3), 58-101.

Bardin, L. (1979). Análise de conteúdo. Lisboa: Edições 70. 
Baruch, Y. (2004). Transforming careers: from linear to multidirectional career paths: organizational and individual perspectives. Career Development International, 9(1), 58-73. doi: $10.1108 / 13620430410518147$

Bendassolli, P. F. (2009). Recomposição da relação sujeito-trabalho nos modelos emergentes de carreira. Revista de Administração de Empresas, 49(4), 387-400. doi: 10.1590/S003475902009000400003

Bresser-Pereira, L. C. (1996). Da administração pública burocrática à gerencial. Revista do Serviço Público, 47(1). Recuperado de http://www.bresserpereira.org.br/papers/1996/95.AdmPublicaBurocraticaAGerencial.pdf

Bresser-Pereira, L. C. (2007). Burocracia pública e classes dirigentes no Brasil. Revista de Sociologia e Política, (28), 9-30. doi: 10.1590/S0104-44782007000100003

Bresser-Pereira, L. C. (2008). O modelo estrutural de gerência pública. Revista de Administração Pública, 42(2), 391-410. doi: 10.1590/S0034-76122008000200009

Bryman, A. (1988). Quantity and quality in social research. London: Unwin Hyman.

Carvalho, A. M. de, Neto (1997). O Estado concorrencial e as mudanças na natureza do trabalho no setor público. Revista de Administração Contemporânea, 1(2), 25-43. doi: 10.1590/S141565551997000200003

Chanlat, J. F. (1995). Quais carreiras e para qual sociedade? (I). Revista de Administração de Empresas, 35(6), 67-75. doi: 10.1590/S0034-75901995000600008

Chanlat, J. F. (1996). Quais carreiras e para qual sociedade? (II). Revista de Administração de Empresas, 36(1), 13-20. doi: 10.1590/S0034-75901996000100003

Coelho, J. A. (2006). Organizações e carreiras sem fronteiras. In M. Balassiano \& I. S. A. da Costa (Orgs.), Gestão de carreiras: dilemas e perspectivas (pp. 95-108). Rio de Janeiro: Editora Atlas.

Corrêa, I. M. (2007). Planejamento estratégico e gestão pública por resultados no processo de reforma administrativa do estado de Minas Gerais. Revista de Administração Pública, 41(3), 487-504. doi: 10.1590/S0034-76122007000300006

Creswell, J. W. (2007). Projeto de pesquisa: métodos qualitativo, quantitativo e misto (2a ed.). Porto Alegre: Artmed.

Decreto n. 5.707, de 23 de fevereiro de 2006. (2006). Institui a política e as diretrizes para o desenvolvimento de pessoal da administração direta, autárquica e fundacional, e regulamenta dispositivos da Lei n. 8.112 de 11 de dezembro de 1990. Recuperado de http://www.planalto.gov.br/ccivil_03/_Ato2004-2006/2006/Decreto/D5707.htm

Dutra, J. S. (1992). Carreiras paralelas: uma proposta de revisão da administração de carreiras. Revista de Administração, 27(4), 65-73.

Evans, P. (1996). Carreira, sucesso e qualidade de vida. Revista de Administração de Empresas, 36(3), 14-22. doi: 10.1590/S0034-75901996000300003

Ferreira, C. M. M. (1996). Crise e reforma do Estado: uma questão de cidadania e valorização do servidor. Revista do Serviço Público, 47(3), 5-33. Recuperado de http://www.enap.gov.br/index.php?option=com_docman\&task=cat_view\&gid=816\&Itemid=129

Fudge, C. (1998). Flexibilidade: os riscos em questão. Cadernos ENAP, (16), 128-139.

Gasparini, D. (2007). Direito administrativo (12a ed.). São Paulo: Saraiva. 
Gustafsson, L. (1998). Promover a flexibilidade por meio de políticas salariais: a experiência da administração nacional Sueca. Cadernos ENAP, (16), 37-53.

Hall, D. T., \& Moss, J. E. (1998). The new protean career contract: helping organizations and employees adapt. Organizational Dynamics, 26(3), 22-37. doi: 10.1016/S0090-2616(98)90012-2

Ikari, S. (1998). Aspectos da política de pessoal na função pública japonesa. Cadernos ENAP, (16), 82-90.

Junquilho, G. S. (2004). A ação gerencial "cabocla" no serviço público face às provocações de mudanças do papel do estado no Brasil: o caso do Espírito Santo. In M. de F. Bianco, G. S. Junquilho, \& C. Waiandt (Orgs.), Tecnologias de gestão: por uma abordagem multidisciplinar (pp. 161-174). Vitória: Flor \& Cultura.

Kerr, H. (2006). Desenvolvimento de competências de servidores na administração pública brasileira. Revista do Serviço Público, 57(4), 549-563.

Kilimnik, Z. M., Castilho, I. V. de, \& Sant Anna, A. S. de (2004, setembro). Carreiras em transformação: um estudo de trajetórias, âncoras e metáforas de carreira em associação a representações de competências profissionais. Anais do Encontro Nacional da Associação Nacional de Pós-Graduação e Pesquisa em Administração, Curitiba, PR, Brasil, 28.

Koga, N. M. (2007). Gestão de pessoas na administração pública japonesa. Revista do Serviço Público, 58(1), 97-106. $\quad$ Recuperado de http://www.enap.gov.br/index.php?option=com_docman\&task=doc_download\&gid=2501

Kuin, P. (1968). Management performance in business and public administration. The Academy of Management Journal, 11(4), 371-377. doi: 10.2307/254886

Lacombe, B. M. B., \& Chu, R. A. (2006). Buscando as fronteiras das carreiras sem fronteiras: uma pesquisa com professores universitários em administração de empresas na cidade de São Paulo. In M. Balassiano \& I. S. A. da Costa (Orgs.), Gestão de carreiras: dilemas e perspectivas (pp. 109-133). Rio de Janeiro: Editora Atlas.

Laegreid, P. (1998). Modificações na política de pessoal do setor público norueguês. Cadernos ENAP, (16), 54-65.

Lemos, A. H. C. da (2006). Empregabilidade e individualização da conquista do emprego. In M. Balassiano \& I. S. A. da Costa (Orgs.), Gestão de carreiras: dilemas e perspectivas (pp. 21-64). Rio de Janeiro: Editora Atlas.

Martins, H. T. (2006). Gerenciamento da carreira proteana. In M. Balassiano \& I. S. A. da Costa (Orgs.), Gestão de carreiras: dilemas e perspectivas (pp. 81-93). Rio de Janeiro: Editora Atlas.

Matias-Pereira, J. (2008). Administração pública comparada: uma avaliação das reformas administrativas do Brasil, EUA e União Européia. Revista de Administração Pública, 42(1), 6182. doi: 10.1590/S0034-76122008000100004

McClintock, C. C., Brannon, B., \& Maynard-Moody, S. (1983). Applying the logic of sample surveys to qualitative case studies: the case cluster method. In J. Van Maanen (Ed.), Qualitative methodology (pp. 149-178). Beverly Hills: Sage.

Minayo, M. C. S. (2007). O desafio do conhecimento: pesquisa qualitativa em saúde (10a ed.). São Paulo: Hucitec.

Misoczky, M. C., \& Vieira, M. M. F. (2001). Desempenho e qualidade no campo das organizações públicas: uma reflexão sobre significados. Revista de Administração Pública, 35(5), 163-177. 
Motta, P. R. (2006). Reflexões sobre a customização das carreiras gerenciais: a individualidade e a competitividade contemporâneas. In M. Balassiano \& I. S. A. da Costa (Orgs.), Gestão de carreiras: dilemas e perspectivas (pp. 9-19). Rio de Janeiro: Editora Atlas.

Oliveira, C. G. de (2007). O servidor público brasileiro: uma tipologia da burocracia. Revista do Serviço Público, 58(3), 269-302. Recuperado de http://www.enap.gov.br/index.php?option=com_docman\&task=cat_view\&gid=807\&Itemid=129

Paulista, J. E. S. (2004). A motivação dos servidores públicos federais, no âmbito dos Ministérios, frente às premissas de valorização firmadas no Plano Diretor da Reforma do Aparelho do Estado, de 1995, e às consequentes ações de gestão de recursos humanos (Dissertação de mestrado). Fundação Getúlio Vargas, Rio de Janeiro, RJ, Brasil.

Salles, D. M. R., \& Nogueira, M. G. (2006). Carreiras no serviço público federal: antigos dogmas, novas perspectivas. In M. Balassiano \& I. S. A. da Costa (Orgs.), Gestão de carreiras: dilemas e perspectivas (pp. 134-149). Rio de Janeiro: Editora Atlas.

Saravia, E. (2006). O sistema de carreira no setor público: descrição análise comparativa e perspectiva. In M. Balassiano \& I. S. A. da Costa (Orgs.), Gestão de carreiras: dilemas e perspectivas (pp. 150-178). Rio de Janeiro: Editora Atlas.

Scheible, A. C. F., \& Bastos, A. V. B. (2006, setembro). Comprometimento com a carreira: explorando o conceito de entrincheiramento. Anais do Encontro Nacional da Associação Nacional de Pós-Graduação e Pesquisa em Administração, Salvador, BA, Brasil, 30.

Schein, E. H. (1984). Culture as an environmental context for careers. Journal of Occupational Behaviour, 5(1), 71-81. doi: 10.1002/job.4030050107

Schein, E. H. (1996). Career anchors revisited: implications for career development in the 21st century. Academy of Management Executive, 10(4), 80-88. doi: 10.5465/AME.1996.3145321

Secchi, L. (2009). Modelos organizacionais e reformas da administração pública. Revista de Administração Pública, 43(2), 347-369. doi: 10.1590/S0034-76122009000200004

Siqueira, M. V. S., \& Mendes, A. M. (2009). Gestão de pessoas no setor público e a reprodução do discurso do setor privado. Revista do Serviço Público, 60(3), 241-250.

Soares, D. H. P., \& Sestren, G. (2007). Projeto profissional: o redimensionamento da carreira em tempos de privatização. Psicologia \& Sociedade, 19(1), 66-74. Recuperado de http://www.scielo.br/pdf/psoc/v19nspe/v19nspea10.pdf. doi: 10.1590/S010271822007000400010

Thiry-Cherques, H. R. (2006). Individualismos e carreira: o duplo constrangimento. In M. Balassiano \& I. S. A. da Costa (Orgs.), Gestão de carreiras: dilemas e perspectivas (pp. 20-48.). Rio de Janeiro: Editora Atlas.

Vergara, S. C. (2008). Métodos de pesquisa em administração (3a ed.). São Paulo: Atlas.

Vieira, M. M. F. (2006). Por uma boa pesquisa (qualitativa) em administração. In M. M. F. Vieira \& D. M. Zouain (Orgs.), Pesquisa qualitativa em Administração (pp. 13-28). Rio de Janeiro: Editora FGV.

Yin, R. K. (1994). Case study research, design and methods. Thousand Oaks: Sage Publications. 